\title{
The effect of cigarette smoking on subjective well-being in South Africa and its implications for tobacco control
}

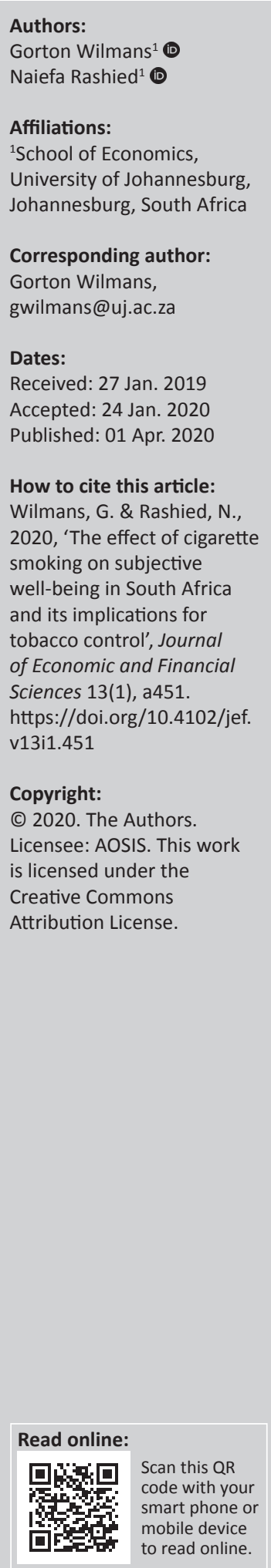

Orientation: The effect of cigarette smoking on health and economic well-being has been widely studied. Its effect on subjective well-being measures, such as life satisfaction, has received less scholarly attention.

Research purpose: This study tested the effect of cigarette smoking on life satisfaction amongst smokers in South Africa as a precursor to assessing the effectiveness of traditional tobacco control methods.

Motivation for the study: Taxation has long been the primary tool for tobacco control in South Africa; however, the psychological effects of cigarette smoking are not considered when selecting tobacco control tools.

Research approach/design and method: The study applied an ordered probit regression to a panel of five waves of the National Income Dynamics Study (NIDS) data to test the relationship between cigarette smoking and life satisfaction in South Africa.

Main findings: Smoking was found to negatively affect an individual's likelihood of reporting higher satisfaction with life relative to non-smokers, a finding that is in line with the limited literature on the subject and with the findings of similar studies that used objective measures of well-being. Furthermore, the current tobacco control framework is not as effective as expected as smoking prevalence is fairly constant, notably amongst the poor, despite large increases in excise duties on cigarettes over time.

Practical/managerial implications: The study's main finding promotes the case for reassessing the approach taken to formulating tobacco control policies and for implementing alternative tobacco control policies that consider the psychological effects of cigarette smoking. As smoking cessation is shown to increase the likelihood of reporting higher life satisfaction, measures aimed at cessation (such as broad-scale smoking bans) could prove more successful than taxation.

Contribution/value-add: This study contributes to the limited literature regarding the relationship between subjective well-being and cigarette smoking in the developing world. The study provides insight to whether standard tobacco control policies should be applied generically without accounting for the relationship between cigarette smoking and subjective well-being.

Keywords: subjective well-being; cigarette smoking; life satisfaction; tobacco control; health economics.

\section{Introduction}

With an output value of $\$ 770$ billion in 2016 , the tobacco industry is a major contributor to the global economy, making cigarette smoking an important economic phenomenon (British American Tobacco 2017). Despite its economic significance, the adverse health and environmental effects of cigarette smoking have become more evident, and subsequently more examined, in the second half of the 20th century (Doll et al. 2004).

In South Africa and around the world, the debate on tobacco control is ongoing with respect to the extent to which cigarette smoking could be controlled and the economic and social effects of this control. On the one hand, tobacco control is of particular relevance in the developing world where the poor tend to become dependent on addictive substances such as nicotine (Bobak et al. 2000; Van Walbeek 2005b; World Health Organization [WHO] 2004). On the other hand, the tobacco 
industry, groups advocating economic freedom and governments could place limitations on the extent to which tobacco control policies could be applied because of the revenue generated from excise-related tobacco control policies. Whilst some countries have significantly increased the aggressiveness of their tobacco control measures in recent years, many others, particularly in the developing world, are slow to follow suit (Bilano et al. 2015; Van Walbeek 2005b). As a result, producers of tobacco products have directed considerably more effort towards increasing sales of tobacco products in developing countries (Mackay \& Crofton 1996).

In addition to the health and environmental effect of tobacco control policies, assessing the relationship between cigarette smoking and subjective measures of well-being may provide useful insights into tobacco use, providing another avenue for assessing tobacco control policy (Wang et al. 2014). The logic behind this assertion is intuitively derived from the association between psychological well-being and addiction, and from the finding that subjective (e.g. happiness and life satisfaction) and objective (e.g. physical health, employment status and income) measures of well-being are correlated (Oswald \& Wu 2010).

Since the beginning of the 21st century, the study of subjective well-being has gained popularity within the social sciences and in the field of economics. This is evident in the increasing amount of research in this field and the number of new academic journals dedicated specifically to the study of wellbeing and happiness, such as the Journal of Happiness Studies, the International Journal of Well-being and the International Journal of Happiness and Development. Many economic phenomena, including cigarette smoking, are being reassessed in the economics literature with a focus on subjective wellbeing alongside or rather than pure economic well-being. The relationship between smoking and subjective well-being has garnered some interest in the literature because subjective measures of well-being provide a new dimension for assessing overall well-being, which can be associated with health and socio-economic status (Wang et al. 2014).

Studies have attempted to measure the effects of abstaining from smoking cigarettes (quitting) on subjective well-being (Dawkins, Acaster \& Powell 2007; Shahab \& West 2012; Weinhold \& Chaloupka 2016), the effects of smoking bans at public places on the self-reported well-being of smokers (Brodeur 2013) and determining whether smoking makes people happy, or is it unhappiness that leads to cigarette smoking (Chang et al. 2015). These studies apply a broad range of inferential, cross-sectional and panel methods of analysis, ranging from experimental studies and Analysis of Variance (ANOVA) to logistic regressions and panel fixedeffects models. The general consensus amongst researchers, irrespective of the method used, is that smoking negatively affects subjective well-being.

Despite the growing literature assessing the relationship between smoking and subjective well-being, the literature specifically focused on developing countries remains limited. A study in Ghana by Yawson et al. (2013) introduced life satisfaction, measured subjectively, as one of the number of variables affected by smoker status in older adults. Besides this, the literature explicitly testing this relationship for developing countries is severely lacking.

As the research on this topic in less developed countries is very limited and because understanding the relationship between cigarette smoking and subjective well-being can provide insight into the social efficiency of different tobacco control policies, this study aimed to examine the relationship between cigarette smoking and subjective well-being in South Africa by testing whether smokers were less likely to report high life satisfaction scores than non-smokers. This study adds to the limited literature studying the relationship between subjective well-being and cigarette smoking in the developing world and provides insight to whether standard tobacco control policies should be applied generically without accounting for the relationship between cigarette smoking and subjective wellbeing. This study applies an ordered probit regression to a panel of five waves of the National Income Dynamics Study (NIDS) data, compiled from a comprehensive South African household survey facilitated by the Southern Africa Labour and Development Research Unit (SALDRU, 2016).

The article is organised as follows: the 'Literature review' section examines the literature related to the relationship between cigarette smoking and subjective well-being as well as the history and current state of tobacco control policy both globally and in South Africa. The 'Data and analysis' section outlines the data and analysis used in this study. The 'Results' section discusses the results and findings of the study, and the 'Limitations, recommendations and conclusion' section outlines possible implications of tobacco control policy in the context of a developing country, such as South Africa, as well as limitations of the study.

\section{Literature review}

The literature suggests that cigarette smoking occurs for a variety of reasons. Ho (1989), in a multi-stage factor analysis relying on small-sample survey data and interviews, identified two primary reasons for peoples' smoking habits. Firstly, people start smoking because they believe that smoking makes them 'feel good'. This could be linked to the culture of smoking that was cultivated in the early- to mid-20th century by cigarette manufacturers through rigorous marketing strategies, which have remained in place and continue to influence potential smokers today (Centers for Disease Control 2012). Secondly, people continue to smoke (whether or not it makes them feel good) because they develop an addiction.

This two-fold explanation creates a premise for assessing the effect of cigarette smoking on subjective measures of wellbeing alongside objective measures of well-being. Since the inception of the idea of tobacco control, the literature has clearly argued that smoking negatively affects objective well- 
being primarily through economic well-being (wealth) and physical well-being (health) effects (WHO2004). Subsequently, the adverse effects of cigarette smoking on wealth and health have motivated tobacco control policy around the world.

What is less common in the public health and health economics literature is the study of how cigarette smoking affects subjective well-being - life satisfaction or happiness, testing whether smoking does indeed make people 'feel good' - and how this relationship could inform policymakers (Wang et al. 2014).

\section{Cigarette smoking and subjective well-being in the literature}

With the rise in popularity of non-economic measures of wellbeing, the relationship between cigarette smoking and happiness has slowly gained popularity in the literature. Shahab and West (2012) suggest that understanding this relationship is important for the ongoing efforts to pass efficient tobacco control policies around the world. Seeking to understand the relationship between smoking and subjective well-being measures makes sense because policymakers should take into account the social and economic impact of policies and their effect on the subjective and objective wellbeing of an individual. Because subjective and objective measures of well-being typically correlate, subjective wellbeing serves as a useful complementary measure of wellbeing (Oswald \& Wu 2010).

Amongst the earliest research assessing this relationship is a study by Adan and Sánchez-Turet (2000). The authors surveyed 42 respondents (half of whom were smokers) every hour to determine mood sensitivity to nicotine consumption and deprivation. Findings suggest that smokers tend to report being in worse moods than non-smokers over the course of a day and exhibit lower levels of happiness than non-smokers regardless of their background or time of the day (KoivumaaHonkanen et al. 2003). These findings suggest that despite smokers perceiving themselves as happier, cigarette smoking causes decrease in smokers' general happiness levels relative to non-smokers.

Dawkins et al. (2007) conducted a social experiment wherein 29 self-identified smokers, who had been allocated to either an abstinent or a satiated state (abstinent smokers had gone without a cigarette for a length of time, whilst satiated smokers had been allowed to have a cigarette right before the test was conducted), were paired with 15 non-smokers to take part in a single interview session. During the session, each participant reported, firstly, emotional responses to nicotine withdrawal and, secondly, reactions to different videos; each meant to elicit positive (happy), neutral or negative (sad) emotional responses. The authors found that abstinent smokers, when compared with satiated smokers, rated positive videos as causing them to feel significantly less 'happy', independent of self-reported nicotine withdrawal symptoms. Non-smokers reported higher levels of happiness than both groups of smokers. 'Sadness' felt in response to negative videos was unaffected by smoking status. These results seem to indicate that the effect of cigarette smoking on happiness is not simply an overall dulling of emotions but rather that the effect occurs only at the positive end of the emotional spectrum. The authors further argue that smokers were unhappier in general.

Similarly, Shahab and West (2012) used a series of analytical techniques to analyse nationally representative data, gathered across England, to assess the relationship between subjective well-being and cigarette smoking after controlling for socio-economic and demographic confounders. The authors initially made use of $\chi^{2}$ tests to examine independence between variables and one-way ANOVAs (for categorical and continuous variables) to detect possible unobserved or confounding relationships using a basket of socio-economic and demographic variables. The aim of identifying and adjusting for confounders stems from the idea that cigarette smoking and subjective well-being (as variables of interest) are likely to be associated with a number of socio-economic and demographic factors that, if not controlled for, could skew estimations. The authors followed this step by estimating simple linear regressions. These baseline estimates were used to identify the association of smoking status with subjective well-being levels without controlling for confounders - to test whether or not controlling for confounders is necessary. Thereafter, the authors included relevant confounders in a series of both simple (with either well-being or the enjoyment of smoking as a dependent variable) and multivariate linear regressions (with both well-being and enjoyment as dependent variables) to evaluate which of the variables, if any, were independently linked with subjective well-being. The authors found that once confounders such as age, gender and social grade are adjusted for, non-recent ex-smokers reported higher well-being than smokers and comparable levels to respondents who had never been smokers. Recent ex-smokers (of less than a year) showed similar well-being levels to current smokers. Furthermore, as reasons given for cigarette smoking, 'to feel less depressed or anxious' was the only smoking characteristic that showed a significant causal link with lower well-being amongst current smokers. The authors concluded that smoking causes lower levels of self-reported well-being and that levels of well-being tend to return to normal after quitting. Furthermore, the authors' findings highlight the importance of adjusting for confounders to make an accurate assessment of the relationship between cigarette smoking and subjective well-being.

Wang et al. (2014) assessed the relationship between cigarette smoking and two subjective measures of well-being for Chinese adults living in Hong Kong. The authors made use of a logistic regression to generate odds ratios, using data gathered via telephone surveys conducted between 2009 and 2012 with 4553 respondents. Using descriptive statistics and correlation tests, the authors found that both non-smokers and ex-smokers reported higher levels of subjective wellbeing than current smokers on both of the scales used in the survey. Odds ratios from the logistic regression confirmed these statistical inferences. The authors found that an ongoing 
attempt to quit was positively associated with higher selfreported well-being, whilst a failed attempt to quit resulted in a temporary drop in well-being. These results also suggest that quitting smoking successfully is likely to increase subjective well-being levels.

In the Netherlands, Weinhold and Chaloupka (2016) assessed the relationship between cigarette smoking and subjective well-being by examining individuals at a specific point in time and over time by using the Longitudinal Internet Studies for the Social Sciences (LISS) survey dataset, which has over 5000 respondents. The authors' emphasis was placed on the effect of smoking cessation (quitting) on self-reported wellbeing and it was found that after quitting, ex-smokers showed a large and significant increase in subjective wellbeing over time. Furthermore, the authors found that smokers who quit willingly, in less stringent regulatory environments, and those who quit as a result of stricter regulation, showed no significant differences in the ensuing subjective well-being effect. The authors' most important conclusion is that despite objections from activist groups, smokers do not suffer a loss in subjective well-being if they are forced to quit (e.g. as a result of the implementation of strict blanket bans on smoking in all public places).

A recent study by Chang et al. (2015) assessed the relationship between cigarette smoking and subjective well-being in an unconventional way by applying the bootstrap causality test on macroeconomic data for five developed countries (Japan, France, Germany, Britain and the United States) using national per capita data on cigarette consumption and subjective well-being. The results, by Granger-causality, suggest a unidirectional causal relationship from well-being to smoking in three of the five countries (Japan, Britain and France). This finding is an indication that 'less happy' people tend to become cigarette smokers. The study also shows that people who smoke cigarettes regularly tend to smoke less when they are 'happier' - pursuant with the findings of other studies that smoking cigarettes does not lead to greater subjective well-being. However, the study is limited because it does not examine the effect of smoking on a person's wellbeing after becoming a smoker or after quitting, nor at the individual level.

Barros et al. (2015), after applying a series of descriptive and inferential techniques, used a two-way ANOVA and simplified rank bi-serial correlation for non-normal distributions to test data collected in Brazil. Using the Five Facet Mindfulness Questionnaire, the Fagerström Test for Nicotine Dependence and the global subjective well-being scale for 181 respondents, the authors found that current smokers are less mindful of what they are feeling and experiencing and less happy in general than non-smokers. They also found that smokers report more severely negative responses to negative situations within the well-being questionnaire relative to non-smokers, indicating a general 'unhappiness' amongst smokers. This, again, is in line with the view that cigarette smoking affects negatively on subjective well-being.

\section{The state of tobacco control}

The concept of tobacco control became prominent internationally between 1993 and 2003, with the conception, drafting and adoption of the WHO's Framework Convention on Tobacco Control (FCTC). The FCTC outlines a set of procedures and norms, initially adopted in 180 countries, for enforcing tobacco control policies (Murphy 2003).

In 1997, prior to the drafting of the FCTC, the WHO commissioned over 40 global specialists in the fields of health economics, epidemiology, public health and tobacco control to study the state of knowledge about tobacco control globally. The combined aim of these studies was to provide a rigorous and complete pool of evidence for the design of impactful tobacco control policies in any country, with particular attention given to the requirements of low- and middle-income countries, where smoking was then found to be prominent.

Jha and Chaloupka (2000) summarised the most significant findings of these studies and presented them to the WHO. Firstly, the studies agreed that tax increases were the single most effective policy, of any policy measure applied in isolation, for reducing the demand for tobacco products. The consensus was that tax increases that raised the real price of cigarettes by $10 \%$ would lead to decrease in cigarette smoking by about $4 \%$ in high-income countries, and by about $8 \%$ in middle- and low-income countries. Secondly, the authors found that developments in the quality and range of educational information sources, strict bans on tobacco advertising, strict enforcement of bans on smoking in all public places and improved access to subsidised nicotine-replacement treatments or smoking-cessation treatments are effective in reducing smoking prevalence, especially in lower-income countries. Thirdly, restricting the supply of tobacco products did not help in reducing the prevalence of tobacco consumption but, in some cases, appeared to exacerbate illegal tobacco trade.

Later, Chaloupka, Straif and Leon (2010) examined a range of research papers authored by over 20 experts in economics, epidemiology, public policy and tobacco control. In an effort to evaluate the reliability and weight of the evidence available on the effectiveness of tax policies and price policies in preventing or reducing the demand for tobacco, the studies surveyed were based on data from 12 different countries, including nine developed ones, and covered a range of aspects related to demand-based tobacco controls, including industry price determination strategies, lobbying by the tobacco industry on tax-related matters, taxes on cigarette prices, aggregate demand for tobacco products with a focus on cigarettes, relationships between taxes and adult tobacco use and the effects of taxation on public health and economies. Eighteen common conclusions were drawn from the survey of studies, 12 of which the authors supported unconditionally, based on the theoretical soundness of the studies' propositions and robustness of the methodologies applied in each study. The most important of these conclusions was strong evidence of the effectiveness of tobacco taxes and increased prices of tobacco products in decreasing overall consumption of 
tobacco products and the prevalence of tobacco use. Moreover, the authors found that higher tobacco taxes were most effective in decreasing demand for tobacco products when paired with other, more passive policies - such as wellmarketed national education schemes on the dangers of cigarette smoking and tobacco use as well as governmentsubsidised therapy-based interventions to help with voluntary smoking cessation.

In 2015, taxation was still the most effective and widely used method for reducing tobacco demand internationally, as indicated in the WHO's (2015) Global Report on Trends in Prevalence of Tobacco Smoking. Countries on the list that have implemented a comprehensive mix of policies to complement tobacco taxation show more promising results. Bilano et al. (2015) applied Bayesian Hierarchical meta-regression models and found that countries with a mix of comprehensive policies, besides taxation, showed substantial projected decrease in the prevalence of tobacco consumption, whilst countries that relied too heavily on taxation and did not incorporate other tobacco control policies (generally developing or low-income countries) showed worsening projected figures, with rising real demand for tobacco products. The authors concluded that action is necessary to attain and sustain desired trends for tobacco control.

It is clear from the general findings of studies that incorporating taxes (which target demand only) complemented by a range of support policies to address the highly addictive nature of tobacco products, such as the provision of information about tobacco products, aggressive educational campaigns and access to assistance in tobacco cessation efforts, have always proven more effective in reducing the prevalence of tobacco use. However, in South Africa, the emphasis continues to lie very heavily on taxation.

\section{Tobacco control policies in South Africa}

South Africa first implemented tobacco control policies in 1993. The primary deterrent to cigarette smoking in South Africa is meant to be the excise tax levied on cigarettes. Between 1994 and 1997, the effective rate of taxation on cigarettes was increased from $21 \%$ to $50 \%$ of the retail price of cigarettes, and this increase has been maintained since. The observed increase has also far exceeded the average inflation rate over this period.

The advertisements of cigarettes and other tobacco products were also banned in the broad media (although advertisements are still allowed in some places - e.g. supermarkets' cigarette kiosks). The effectiveness of this technique in lowering the incidence of cigarette smoking is questionable because smoking is a very visible habit in both real world and popular culture.

Whilst other policies introduced include bans and restrictions on cigarette smoking in many public places, these are often not enforced because of the lack of capacity by law enforcement and bribery, corruption or complacency by the general public (Blecher 2010; Van Walbeek 2005a).
Furthermore, whilst programmes to educate individuals about the dangers of cigarette smoking or to counsel addicts who would like to quit do exist, these are neither well publicised, well funded nor easily accessible to the general public.

\section{Tobacco control policies and well-being}

Whilst taxation is known to be one of the most effective forms of tobacco control, it may also be the most damaging to lowincome groups (Remler 2004). This view stems from the argument that taxation on tobacco products is regressive and, as a result, places a greater burden on individuals with lower incomes. This phenomenon is explored by Borren and Sutton (1992), who, by analysing the Tobacco Advisory Council surveys, drew price elasticities to establish the effect of price changes on different social classes. These authors found no clear pattern in the responsiveness of smoking behaviour to prices across different social classes. In dividing the dataset into five distinct social classes, the authors found that people in the lowest class could expect to pay 8-11 times more of tax increase when compared with people in the highest class. The authors concluded that, relative to income, the regressivity of increase in tobacco taxation is prominent.

Franks et al. (2007) furthered this research by calculating and analysing price elasticities using data from the American Behavioural Risk Factor Surveillance System survey dataset from 1984 to 2004. The elasticities were drawn for different income groups, and when compared with market trends, increase in the real price of cigarettes over time was associated with a notable drop in the number of cigarette smokers amongst higher-income groups but not amongst lower-income groups. Whilst the reasoning for this finding is not within the study's scope, the finding does provide valuable insight into the income-related disparities in cigarette smoking and shows that tobacco taxation places a disproportionate burden on the poor. The study's results highlight the view that taxation might not be an effective tool for tobacco control for poorer populations and may even prove more damaging than effective in cases where cigarette smokers are poor.

Similarly, in a study by Farrelly, Nonnemaker and Watson (2012), data from the New York State Adult Tobacco Survey (ATS) and the US Adult Tobacco Survey from 2010 to 2011 were analysed using descriptive statistics and a multiple regression to investigate the relationship between three variables, namely, smoking prevalence, daily cigarette consumption and share of annual income spent on cigarettes. Whilst it was found that taxation remains an effective tool for decreasing the incidence of cigarette smoking, the authors also highlighted that tobacco taxation places a severe financial burden on poor smokers, the group of people that accounted for the largest proportion of all smokers in the study.

It is reasonable to assume that any policy action that has a severe negative effect on the economic well-being of individuals will also impact negatively on their subjective well-being. This is because, as the literature suggests, there is a positive relationship between income or expenditure (the 
common proxies for economic well-being) and subjective well-being (Frey 2008; Frey et al. 2010).

This literature review suggests that the prominent view amongst researchers is that the application of non-tax policies which effectively force cigarette smokers to quit will not adversely affect their happiness. Furthermore, the literature suggests that cigarette smoking not only damages the smoker's health and the smoker's economic (objective) well-being, it also has a significant damaging psychological effect, that is, it damages the smoker's self-reported (subjective) well-being.

This implies that placing too much emphasis on taxation policies may not necessarily address the psychological impact of smoking. Barros et al. (2015) recommend that policymakers focus on putting in place programmes that focus on providing mindful-based interventions such as therapies aimed at educating smokers about the damaging effect smoking is having on their psychological well-being and helping smokers to overcome their addiction by making use of meditation techniques, breathing exercises and 'feelings management'. Brodeur (2013), in the analysis of the effectiveness of smoking bans across the United States over a 20-year period, found that smokers who wanted to quit experienced higher levels of subjective well-being as a result of these bans, possibly interpreting bans as a source of motivation to succeed. This suggests that smokers who wish to quit are more likely to quit if bans make it more difficult for them to smoke freely.

Yang and Zucchelli (2015) found similar results in a study conducted in the United Kingdom. They estimated flexible difference-in-differences and fixed-effects models on data from the British Household Panel Survey and found that smokers, especially males who are married and have dependent children, experienced a significant increase in their subjective well-being as a result of smoking bans in public places in England and Scotland.

Odermatt and Stutzer (2014) assessed the effects of both price increase of cigarettes and smoking bans in Europe, using data from 40 European countries over a 21-year period, using fixed-effects regression models that control for time, location and economic factors. It was found that higher prices of cigarettes significantly reduce the well-being of cigarette smokers. The authors also found that smoking bans have no effect on the well-being of cigarette smokers who are determined not to quit.

A study conducted in a developing country presents similar results. Yawson et al. (2013) assess the later-life effects of tobacco consumption in Ghana. Amongst these effects is the effect on life satisfaction. The authors made use of a nationally representative dataset drawn from a survey conducted across 4305 older adults by the WHO. Applying logistic regressions adjusted for age, sex and other social and demographic factors to obtain adjusted odds ratios, it was found that life satisfaction is likely to be significantly lower for those who consume tobacco than for those who do not. The authors also found that people who had consumed tobacco in their youth but stopped later in life exhibit levels of life satisfaction comparable to those who had never consumed tobacco. Increased and easily accessible information about the dangers of tobacco use was identified as a prominent factor in individuals making the decision to stop using tobacco products, whilst price-control measures were not provided as a prominent factor.

The literature presented in this section suggests a favourable case for the use of strict, broad-based smoking bans as effective tobacco control policy tools because studies show that these bans not only benefit non-smokers but also the smokers themselves from both economic and non-economic standpoint. The literature also suggests that taxation policies, especially in isolation, are not socially efficient as they harm smokers' subjective well-being and do not effectively motivate them to quit smoking.

\section{Data and analysis}

The data used in this study are from NIDS (SALDRU, 2016), which has proven appropriate for subjective well-being analysis in previous research (Ebrahim, Botha \& Snowball 2013). The study makes use of a panel consisting of fives waves of the NIDS data published between 2008 and 2018.

The variables used are as follows: life satisfaction, measured on a Cantril-type scale, serves as a proxy for subjective well-being, and smoking status was recorded as a standard dummy variable, with 1 representing 'the respondent smokes cigarettes'. Pursuant with the subjective well-being literature, a set of confounders was used in our analysis as control variables (Botha 2014; Ebrahim et al. 2013). These are population group, gender, household per capita income, (self-reported) health status, employment status, age and age ${ }^{2}$. The coding of these variables and transformations, where applicable, is shown in Table 1 . In the descriptive analyses, having assessed the baseline results and following the intuition discussed in Winship and Radbill (1994) and Pfeffermann (1993) the data were weighted using the post-stratified probability weights prescribed and provided by NIDS. In the econometric analysis, the NIDS panel weights were used to account for attrition between wave 1 and each consecutive wave.

As a point of departure, Pearson's chi-square $\left(\chi^{2}\right)$ tests of independence were conducted for, firstly, the relationship of interest and then for each confounder with life satisfaction in each wave. All confounding relationships were found to be significant - the $\chi^{2}$ statistics are shown in Table 2.

Because the Cantril Ladder is ordinal in nature, an ordered probit regression is the most appropriate application. This is also in line with the majority of literature. In addition to

TABLE 1: Variables (unweighted sample).

\begin{tabular}{lllc}
\hline Variable & Type & Transformation & Observations \\
\hline Life satisfaction & Ordinal & Non-logical =. & 95774 \\
Smoking status & Binary & Dummy, 1 = smoker, non-logical =. & 97583 \\
Population group & Nominal & Non-logical =. & 189466 \\
$\begin{array}{l}\text { Gender } \\
\text { Share of household } \\
\text { income }\end{array}$ & Binary & Dummy, 1 = male, non-logical =. & 189396 \\
Health & Ordinal & $\begin{array}{l}\text { Inonthly household income/ } \\
\text { household size) }\end{array}$ & 169991 \\
Employment & Binary & Dummy, 1 = employed, non-logical =. & 104201 \\
Age $^{\text {Age }}{ }^{2}$ & Discrete & Non-logical =. & 189161 \\
\hline
\end{tabular}

Note: Non-logical=., Any non-logical responses for this variable were re-coded as missing values. 
modelling change over time, the random effects panel probit model also addresses any endogeneity from two-way causality that may be present in the variables of interest. The possible issue of two-way causality is discussed further in Section 5. In the model, life satisfaction was the dependent variable, smoking status was the independent variable of interest and all of the confounders were included as controls.
Heteroscedasticity-consistent standard errors were calculated in each case (Botha 2014; Ebrahim et al. 2013).

\section{Results}

To provide some basic descriptive analysis, the distribution of smokers within each of the socio-economic and demographic control groups was compiled. Table 3 shows the results.

TABLE 2: Tests of independence.

\begin{tabular}{|c|c|c|c|c|c|}
\hline Variables & Wave 1 & Wave 2 & Wave 3 & Wave 4 & Wave 5 \\
\hline Life satisfaction and smoking status & $4.6 \mathrm{e}+06 * * *$ & $8.6 \mathrm{e}+07 * * *$ & $4.0 \mathrm{e}+07 * * *$ & $3.5 \mathrm{e}+07 * * *$ & $3.2 \mathrm{e}+07 * * *$ \\
\hline Life satisfaction and population group & $3.1 \mathrm{e}+06 * * *$ & $5.7 \mathrm{e}+06 * * *$ & $4.4 \mathrm{e}+06 * * *$ & $2.8 \mathrm{e}+06 * * *$ & $1.9 \mathrm{e}+06^{* * *}$ \\
\hline Life satisfaction and gender & $7.4 \mathrm{e}+04 * * *$ & $1.1 \mathrm{e}+05 * * *$ & $7.0 \mathrm{e}+04 * * *$ & $7.2 \mathrm{e}+04 * * *$ & $1.1 \mathrm{e}+05^{* * *}$ \\
\hline Life satisfaction and household per capita income $\dagger$ & $4.8 \mathrm{e}+06 * * *$ & $5.5 \mathrm{e}+06 * * *$ & $4.3 e+06 * * *$ & $3.1 \mathrm{e}+06 * * *$ & $2.6 \mathrm{e}+06 * * *$ \\
\hline Life satisfaction and health & $3.3 e+06 * * *$ & $3.5 \mathrm{e}+07 * * *$ & $3.2 \mathrm{e}+07 * * *$ & $2.5 \mathrm{e}+06 * * *$ & $3.7 \mathrm{e}+07 * * *$ \\
\hline Life satisfaction and employment & $7.9 \mathrm{e}+05 * * *$ & $4.5 \mathrm{e}+06 * * *$ & $1.1 \mathrm{e}+06 * * *$ & $9.9 \mathrm{e}+06 * * *$ & $8.0 \mathrm{e}+06 * * *$ \\
\hline Life satisfaction and age $\dagger$ & $7.0 \mathrm{e}+05^{* * *}$ & $7.6 \mathrm{e}+05 * * *$ & $4.8 \mathrm{e}+05^{* * *}$ & $5.4 \mathrm{e}+05^{* * *}$ & $4.8 \mathrm{e}+05^{* * *}$ \\
\hline Life satisfaction and $a^{2} \mathrm{e}^{2} \dagger$ & $6.9 \mathrm{e}+05^{* * *}$ & $7.6 \mathrm{e}+05 * * *$ & $4.8 \mathrm{e}+05 * * *$ & $5.4 \mathrm{e}+05^{* * *}$ & $4.8 \mathrm{e}+05 * * *$ \\
\hline
\end{tabular}

Note: Analysis uses population-weighted data.

$\dagger$, Variables were categorised as deciles in Stata tabulations to avoid error code 134 (too many values).

$*, p<0.1 ; * *, p<0.05 ; * * *, p<0.001$.

TABLE 3: Distribution - Smoker status.

\begin{tabular}{|c|c|c|c|c|c|}
\hline Variable & Wave 1 & Wave 2 & Wave 3 & Wave 4 & Wave 5 \\
\hline \multicolumn{6}{|c|}{ Percentage of smokers by total population } \\
\hline Smokers & 20.84 & 17.79 & 19.52 & 20.41 & 19.34 \\
\hline \multicolumn{6}{|c|}{ Percentage of smokers by population group } \\
\hline African & 16.57 & 14.03 & 15.88 & 17.10 & 16.24 \\
\hline White & 36.29 & 26.77 & 27.93 & 24.74 & 26.49 \\
\hline Indian or Asian & 21.52 & 19.05 & 18.63 & 20.15 & 24.44 \\
\hline Mixed race & 41.94 & 42.18 & 42.70 & 45.26 & 40.80 \\
\hline \multicolumn{6}{|c|}{ Percentage of smokers by gender } \\
\hline Male & 35.92 & 30.26 & 33.45 & 34.64 & 33.60 \\
\hline Female & 9.02 & 7.18 & 7.71 & 7.90 & 6.87 \\
\hline \multicolumn{6}{|c|}{ Percentage of smokers by income quintile (absolute) } \\
\hline $0 \%-20 \%$ & 15.52 & 11.91 & 13.40 & 14.85 & 14.64 \\
\hline $20 \%-40 \%$ & 14.73 & 12.41 & 13.14 & 16.20 & 17.07 \\
\hline $40 \%-60 \%$ & 18.60 & 17.14 & 18.43 & 19.89 & 18.82 \\
\hline $60 \%-80 \%$ & 23.94 & 18.28 & 22.27 & 24.59 & 21.75 \\
\hline $80 \%-100 \%$ & 25.24 & 22.27 & 22.68 & 21.72 & 20.65 \\
\hline \multicolumn{6}{|c|}{ Percentage of smokers by health status } \\
\hline Poor & 23.48 & 22.53 & 21.39 & 24.54 & 21.38 \\
\hline Fair & 19.69 & 17.36 & 25.83 & 23.36 & 21.03 \\
\hline Good & 19.99 & 18.85 & 19.13 & 21.66 & 20.27 \\
\hline Very good & 21.38 & 17.87 & 20.38 & 20.06 & 18.06 \\
\hline Excellent & 20.68 & 16.99 & 17.44 & 18.55 & 19.24 \\
\hline \multicolumn{6}{|c|}{ Percentage of smokers by employment status } \\
\hline Employed & 27.81 & 24.42 & 26.06 & 26.33 & 24.02 \\
\hline Unemployed & 15.60 & 13.86 & 15.00 & 15.26 & 15.30 \\
\hline \multicolumn{6}{|c|}{ Percentage of smokers by age } \\
\hline $15-35$ years & 17.88 & 15.86 & 17.14 & 18.33 & 18.21 \\
\hline $35-64$ years & 26.19 & 22.46 & 23.71 & 24.14 & 22.66 \\
\hline $65+$ years & 15.30 & 7.94 & 14.98 & 10.98 & 10.29 \\
\hline \multicolumn{6}{|c|}{ Percentage of smokers by province } \\
\hline Western Cape & 36.83 & 35.26 & 34.16 & 36.88 & 30.63 \\
\hline Eastern Cape & 17.07 & 15.36 & 17.37 & 19.02 & 16.56 \\
\hline Northern Cape & 34.97 & 29.66 & 32.36 & 33.2 & 33.16 \\
\hline Free State & 23.70 & 16.91 & 22.33 & 23.29 & 19.70 \\
\hline KwaZulu-Natal & 16.53 & 13.05 & 15.00 & 14.58 & 12.82 \\
\hline North West & 21.47 & 16.83 & 15.55 & 20.74 & 19.79 \\
\hline Gauteng & 20.94 & 19.20 & 21.36 & 20.49 & 21.43 \\
\hline Mpumalanga & 17.31 & 16.92 & 13.01 & 15.92 & 18.00 \\
\hline Limpopo & 14.90 & 8.39 & 12.24 & 12.31 & 12.13 \\
\hline
\end{tabular}

Note: Analysis uses population-weighted data. 
The percentage of the total population that smokes cigarettes remained fairly constant across the five waves. This is worrying because one would expect to find a significant drop in this figure given the intensification of tobacco control in the form of massive tax increases over this period (National Treasury 2014). This figure supports the literature in that taxation, in isolation, is not the most effective form of tobacco control.

A far greater percentage of men reported that they are smokers than do women. Also, it is noteworthy that smoking is more prevalent amongst those who report poor health and smoking is less prevalent amongst those who are from higher-income strata and/or employed than amongst those who are from low-income strata and/or unemployed.

In terms of geographical location, the distribution of smoker prevalence by province is also reported. It can be seen that the provincial distribution of smokers does not remain as stable over the five waves as do most of the other control variables. On the whole, though, information from geographical location does correspond with information captured by the other control variables - smoking is less prevalent in provinces that are both poorer and where African people constitute most of the population (e.g. Limpopo and Mpumalanga,) and is more prevalent in both higher-income provinces and in provinces where population groups with greater smoker prevalence make up more of the population (e.g. Northern and Western Cape and Gauteng). For this reason, and also because of lack of empirical support for its inclusion in the econometric model, geographical location is not included in any further analysis.

In addition, a summary of the mean life satisfaction scores reported by each socio-economic and demographic control group was compiled (see Table 4), and it can be seen that white or Asian/Indian South Africans consistently report the highest life satisfaction scores on average, whilst Africans always report the lowest scores. This is in line with the literature in South Africa (see Hinks \& Gruen 2007, for an earlier discussion). An intuitively sound discovery is that those in higher-income quintiles tend to report higher satisfaction with life - a support for the assertion in the economics literature that money can indeed buy happiness (Diener \& Oishi 2000). Furthermore, those who report being healthier tend to also report being more satisfied with life, and those who are employed also tend to be more satisfied than those who are unemployed. Regarding the two objective measures of well-being included amongst the control variables, income and employment status, the descriptive analysis seems to support the assertion that subjective and objective measures of well-being are correlated (Oswald \& Wu 2010).

In terms of transition dynamics, Table 5 shows that of all sample members who were smokers at any point between waves 1 and 5, 24.91\% stopped smoking between 2008 and 2016 (although data may be missing for some individuals for some waves). Of all the sample non-smokers, $6.05 \%$ began

TABLE 4: Mean values - Life satisfaction.

\begin{tabular}{|c|c|c|c|c|c|}
\hline Variable & Wave 1 & Wave 2 & Wave 3 & Wave 4 & Wave 5 \\
\hline Mean of sample & 5.58 & 4.88 & 4.91 & 5.40 & 5.43 \\
\hline \multicolumn{6}{|c|}{ Mean by population group } \\
\hline African & 5.24 & 4.50 & 4.64 & 5.20 & 5.31 \\
\hline White & 6.93 & 7.22 & 6.89 & 6.84 & 6.97 \\
\hline Indian or Asian & 6.88 & 7.41 & 6.94 & 6.32 & 5.76 \\
\hline Mixed race & 6.46 & 6.19 & 5.52 & 6.24 & 5.91 \\
\hline \multicolumn{6}{|l|}{ Mean by gender } \\
\hline Male & 5.61 & 5.01 & 5.01 & 5.44 & 5.46 \\
\hline Female & 5.56 & 4.95 & 4.97 & 5.50 & 5.52 \\
\hline \multicolumn{6}{|c|}{ Mean by income quintile (household per-capita) } \\
\hline $0 \%-20 \%$ & 4.62 & 3.94 & 3.95 & 4.67 & 4.81 \\
\hline $20 \%-40 \%$ & 4.90 & 4.33 & 4.38 & 4.95 & 4.96 \\
\hline $40 \%-60 \%$ & 5.29 & 4.52 & 4.55 & 5.05 & 5.22 \\
\hline $60 \%-80 \%$ & 5.46 & 4.60 & 4.91 & 5.39 & 5.46 \\
\hline \multicolumn{6}{|c|}{ Mean by health status } \\
\hline Poor & 4.30 & 4.27 & 4.41 & 5.04 & 4.57 \\
\hline Fair & 5.17 & 4.41 & 4.70 & 5.32 & 5.04 \\
\hline Good & 5.34 & 4.55 & 4.81 & 5.43 & 5.41 \\
\hline Very good & 5.89 & 4.89 & 5.21 & 5.41 & 5.55 \\
\hline Excellent & 5.90 & 5.38 & 5.98 & 5.64 & 5.68 \\
\hline \multicolumn{6}{|c|}{ Mean by employment status } \\
\hline Employed & 5.78 & 5.46 & 5.32 & 5.73 & 5.68 \\
\hline Unemployed & 5.43 & 4.70 & 4.77 & 5.25 & 5.34 \\
\hline \multicolumn{6}{|l|}{ Mean by age } \\
\hline $15-35$ years & 5.61 & 4.87 & 4.89 & 5.45 & 5.47 \\
\hline $35-64$ years & 5.53 & 5.08 & 5.08 & 5.46 & 5.48 \\
\hline $65+$ years & 5.64 & 5.28 & 5.27 & 5.73 & 5.77 \\
\hline
\end{tabular}

Note: Analysis uses population-weighted data. 
smoking between two periods. Another notable trend is the relationship between smoking and drinking. Respondents, who reportedly never drink alcohol, also do not smoke. Table 6 shows that those who drink do not necessarily smoke, which is contrary to findings in the literature. Finally, Table 7 shows the results of the ordered probit regression with life satisfaction as the dependent variable, smoking status as the primary explanatory variable and all other confounding variables included as controls. The $\chi^{2}$ statistic of 1290.67 ( $p<$ 0.001 ) indicates that the model is significant and that the explanatory variables included jointly explain the changes in life satisfaction to some extent.

The sign on the coefficient of smoking status is negative as expected, and significant $(p<0.001)$. This supports the postulation that smoking cigarettes causes an individual to be less satisfied with life, that is, less likely to report a higher level

TABLE 5: Transition dynamics for smoker status.

\begin{tabular}{lcc}
\hline Smoker status & Smoker (\%) & Non-smoker (\%) \\
\hline Smoker & 75.09 & 24.91 \\
Non-smoker & 6.05 & 93.95 \\
\hline
\end{tabular}

TABLE 6: Ordered probit (RE) regression results.

\begin{tabular}{lcc}
\hline Dependent: Life satisfaction & Coefficient & Robust SE \\
\hline Smoking status & $-0.145^{* * *}$ & 0.020 \\
Population group (African omitted) & & \\
Mixed race & $0.437^{* * *}$ & 0.026 \\
Indian or Asian & $0.598^{* * *}$ & 0.065 \\
White & $0.675^{* * *}$ & 0.050 \\
Gender (male omitted) & 0.010 & 0.015 \\
Share of household income & $0.001^{* * *}$ & $<0.001$ \\
Health (poor omitted) & & \\
Excellent & $0.370^{* * *}$ & 0.045 \\
Very good & $0.289^{* * *}$ & 0.045 \\
Good & $0.220^{* * *}$ & 0.045 \\
Fair & $0.161^{* * *}$ & 0.047 \\
Employment (unemployed omitted) & $0.198^{* * *}$ & - \\
Age & $-0.018^{* * *}$ & 0.002 \\
Age & $0.001^{2} * *$ & $<0.001$ \\
Pseudo $R^{2}$ (calculated) & 0.062 & - \\
Variance of random effects & $0.055^{*}$ & - \\
Wald's $\chi^{2}$ & $1290.67 * * *$ & - \\
Observations included & 61215, for $i=16$ 779 & - \\
\hline
\end{tabular}

Note: $i$ refers to any individual in the sample.

$\mathrm{SE}$, standard error; RE, random effects.

$*, p<0.1 ; * *, p<0.05 ; * * *, p<0.001$. of satisfaction with life. This finding is in support of the literature surveyed and is important from a policymaking perspective, which will be discussed further in the next section.

The signs on the control variables are also mostly consistent with expectations and all are almost significant at $1 \%$ and are discussed briefly for the sake of completeness. The coefficient on each of the population groups (mixed race, Asian/Indian and white) is positive and significant at $1 \%$. This indicates that, to varying magnitudes, respondents in all of the included population groups are more likely to report a higher life satisfaction score than African respondents. This is in line with the findings in the literature explored by Aldous and Gainey (1999), and Yang (2008) as well as Hinks and Gruen (2007) specifically for South Africa. The sign of the coefficient on gender (where male is equal to 1 ) is positive but insignificant, although this coefficient would indicate that lower life satisfaction is likely to be reported by males than by females. Findings in the literature on this relationship, as explored extensively by Pinquart and Sörensen (2001), are mixed, and it is suggested that the relationship between gender and selfreported well-being is affected, at different ages, by many different things for men and women. Relative income (as represented by an individual's share of household income) exhibits a positive relationship with life satisfaction. This finding makes intuitive sense and is supported by a large body of literature and is explored by Ferrer-i-Carbonell (2005) and Diener and Oishi (2000), who discuss and rationalise the positive association between income levels and levels of happiness or subjective well-being. For self-reported health, all respondents included are more likely to report higher levels of life satisfaction than those who fall in the omitted group, poor. Again, the literature tends to support this, as is explored by Brief et al. (1993), who discuss some of the earliest research on this relationship. People who are employed are likely to report higher satisfaction with life than those who are unemployed again, a finding that makes sense intuitively and is supported concisely by Brereton, Clinch and Ferreira (2008), who explored this relationship for a sample of Irish adults and found a significant negative effect of both unemployment and underemployment on life satisfaction. Age and age ${ }^{2}$ also exhibit appropriate signs, negative and positive, which support the general finding in the literature that age is U-shaped in happiness (or subjective well-being) (Blanchflower \& Oswald 2008; Ebrahim et al. 2013).

TABLE 7: Sensitivity analysis - Smoking and alcohol consumption (wave 4).

\begin{tabular}{|c|c|c|c|c|}
\hline \multirow[t]{2}{*}{ Response } & \multicolumn{2}{|c|}{ Smoker $(x 2=5300.00 \dagger)$} & \multicolumn{2}{|c|}{ Non-smoker $(p=0.000)$} \\
\hline & $n$ & $\%$ & $n$ & $\%$ \\
\hline Never drinks alcohol & 1096346 & 15.00 & 17876446 & 64.20 \\
\hline Gave up drinking alcohol & 1094541 & 15.35 & 3339352 & 11.99 \\
\hline Drinks rarely & 2160709 & 30.30 & 4121259 & 14.80 \\
\hline Drinks less than 1 day a week & 794726 & 11.15 & 820539 & 2.95 \\
\hline Drinks on $1-2$ days a week & 1338469 & 18.77 & 1244927 & 4.47 \\
\hline Drinks on 5-6 days a week & 91149 & 1.28 & 109406 & 0.39 \\
\hline Drinks every day & 148507 & 2.08 & 56345 & 0.20 \\
\hline Total (\%) & 7130423 & 100.00 & 27843097 & 100.00 \\
\hline
\end{tabular}

Note: Analysis uses population-weighted data.

$\dagger$, Scaled to sample. 


\section{Limitations}

The methodology used in this study has two noteworthy limitations. Firstly, a more comprehensive subjective measure of well-being could have been used had one been available. As argued by Hicks (2011), a Cantril Ladder measure of wellbeing has a variety of limitations - the Organisation for Economic Co-operation and Development (OECD, 2011) outlines some of these, focusing on discrepancies arising from personality effects, current mood, cultural norms and relative judgement effects.

Also, as pointed out by Wang et al. (2014), it is difficult to ascertain temporal sequence when considering the two primary variables of interest - cigarette smoking and subjective wellbeing - and so there may be an element of two-way causality in the model. One way of controlling for this is to address the endogeneity resulting from two-way causality. A panel data model is most appropriate as it exploits changes within units over time and subsequently eliminates time-invariant heterogeneity which reduces the risk of confounding' (Leszczensky \& Wolbring 2018). Furthermore, panel data methods are known to assist with determining causal order (Vaisey \& Miles 2017). More specifically, a first-difference (FD) model would have been the most appropriate one, as this model relaxes the assumption of strict exogeneity needed to deal with reverse causality. However, in our case, a random effects model is the most appropriate one as it takes into account the ordinal structure of our variables of interest (Carrière \& Bouyer 2006). Using an instrumental variables approach would provide a more effective and direct solution to the issue of twoway causality using cross-sectional data. However, the NIDS data do not allow for this as there are no appropriate instruments available for either smoker status or life satisfaction.

\section{Recommendations}

As the literature suggests, a mix of tobacco control policies tends to be more effective in reducing the incidence of cigarette smoking, especially in developing countries.

Taxation is known to have a distorting effect, where poorer individuals lose a greater portion of their incomes to tax relative to richer individuals (Farrelly et al. 2012; Franks et al. 2007). In developing countries such as South Africa, where smoking incidence is very high amongst the poor, this distortion is felt more intensely by the poor, as poor people who are determined to continue smoking spend larger portions of their incomes on purchasing cigarettes, often to the detriment of themselves and their dependants. The poor are likely to turn to low-grade, illegal cigarettes which are cheaper but often much more dangerous than the premium, taxed alternatives (Blecher 2010). Therefore, in addressing cigarette smoking through policy responses, it is important to consider the socio-economic effects of different tools.

Because cigarette smokers in South Africa are less likely to report high subjective well-being scores relative to non-smokers, the policies aimed at tobacco control should address, alongside health effects, the financial and psychological effects of smoking cigarettes. In line with the literature, this study recommends that South Africa should focus on measures that heavily emphasise forced cessation and pre-emptive education alongside taxation.

\section{Conclusion}

This study aimed to determine whether smokers in South Africa are less likely to report higher subjective well-being (measured by life satisfaction score) than smokers. In answering this question, the study explored whether this relationship could be used to inform tobacco control policy in South Africa.

We applied an ordered probit regression to a panel of NIDS data, weighted to be nationally representative, and found that cigarette smokers are less likely to report high levels of satisfaction with life than non-smokers. This suggests that smoking has a measurable negative effect on subjective wellbeing and that policies should aim to address this effect by better understanding the root causes. Proven successful in many similar contexts to South Africa, forced cessation measures and intensive pre-emptive education projects are recommended policy responses to be explored to address this relationship.

\section{Acknowledgements}

The authors would like to express their sincere gratitude to Claire Vermaak and Ferdi Botha for the useful comments on this article, which is derived from the minor dissertation entitled 'Smoking and subjective well-being in South Africa'.

\section{Competing interests}

The authors declare that they have no financial or personal relationships that may have inappropriately influenced them in writing this article.

\section{Authors' contributions}

This article is based on a minor dissertation written by G.W. under the supervision of N.R. In the conversion stages, both authors contributed to the editing, reworking and revising of the original work.

\section{Funding information}

This research received no specific grant from any funding agency in the public, commercial or not-for-profit sectors.

\section{Data availability statement}

Data sharing is not applicable to this article as no new data were created or analysed in this study.

\section{Disclaimer}

The views and opinions expressed in this article are those of the authors and do not necessarily reflect the official policy or position of any affiliated agency of the authors. 


\section{References}

Adan, A. \& Sánchez-Turet, M., 2000, 'Effects of smoking on diurnal variations of subjective activation and mood', Human Psychopharmacology: Clinical and Experimental 15(4), 287-293. https://doi.org/10.1002/1099-1077(200006) 15:4<287::AID-HUP175>3.0.CO;2-L

Aldous, J. \& Ganey, R.F., 1999, 'Family life and the pursuit of happiness: The influence of gender and race', Journal of Family Issues 20(2), 155-180. https://doi. org/10.1177/019251399020002001

Barros, V.V., Kozasa, E.H., Formagini, T.D.B., Pereira, L.H. \& Ronzani, T.M., 2015, 'Smokers show lower levels of psychological well-being and mindfulness than non-smokers', PLoS One 10(8), e0135377. https://doi.org/10.1371/journal.pone.0135377

Bilano, V., Gilmour, S., Moffiet, T., D’Espaignet, E.T., Stevens, G.A., Commar, A. et al., 2015, 'Global trends and projections for tobacco use, 1990-2025: An analysis of smoking indicators from the WHO comprehensive information systems for smoking indicators from the WHO comprehensive information systems for tobacco control',

Blanchflower, D.G. \& Oswald, A.J., 2008, 'Is well-being U-shaped over the life cycle?', Social Science \& Medicine 66(8), 1733-1749. https://doi.org/10.1016/j. socscimed.2008.01.030

Blecher, E., 2010, 'A mountain or a molehill: Is the illicit trade in cigarettes undermining tobacco control policy in South Africa?' Trends in Organized Crime 13(4), 299-315. https://doi.org/10.1007/s12117-010-9092-y

Bobak, M., Jha, P., Nguyen, S. \& Jarvis, M., 2000, 'Chapter 3: Poverty and smoking', in P. Jha \& F. Chaloupka (eds.), Tobacco control in developing countries, pp. 41-62, Oxford University Press, New York (on behalf of the World Health Organization and the World Bank).

Borren, P. \& Sutton, M., 1992, 'Are increases in cigarette taxation regressive?' Health Economics 1(4), 245-253. https://doi.org/10.1002/hec.4730010406

Botha, F., 2014, 'Life satisfaction and education in South Africa: Investigating the role of attainment and the likelihood of education as a positional good', Social Indicator Research 118(2), 555-578. https://doi.org/10.1007/s11205-013-0452-2

Brereton, F., Clinch, J.P. \& Ferreira, S., 2008, 'Employment and life-satisfaction: Insights from Ireland', Economic \& Social Review 39(3), 207-234.

Brief, A.P., Butcher, A.H., George, J.M. \& Link, K.E., 1993, 'Integrating bottom-up and topdown theories of subjective well-being: The case of health', Journal of Personality and Social Psychology 64(4), 646. https://doi.org/10.1037//0022-3514.64.4.646

British American Tobacco, 2017, The global market, viewed 09 April 2017, from http://www.bat.com/group/sites/UK 9D9KCY.nsf/vwPagesWebLive/DO9DCKFM.

Brodeur, A., 2013, 'Smoking, income and subjective wellbeing: Evidence from smoking bans', IZA discussion paper series DP7357, viewed 7 March 2018, from http://ftp.iza.org/dp7357.pdf.

Carrière, I. \& Bouyer, J., 2006, 'Random-effect models for ordinal responses: Application to self-reported disability among older persons', Epidemiology and Public Health/Revue d'Epidémiologie et de Santé Publique 54(1), 61-72. https://doi.org/10.1016/s0398-7620(06)76695-0

Centers for Disease Control, 2012, Preventing tobacco use among youth and young adults: A report of the surgeon general. Atlanta (GA) - 5: The tobacco industry's influences on the use of tobacco among youth, viewed 9 March 2018, from https://www.ncbi.nlm.nih.gov/books/NBK99238/.

Chaloupka, F., Straif, K. \& Leon, M.E., 2010, 'Effectiveness of tax and price policies in tobacco control', Tobacco Control 20(3), 235. http://doi.org/10.1136/tc.2010.039982

Chang, T., Chu, H.P., Deale, F.W. \& Gupta, R., 2015, 'The causal relationship between happiness and smoking: A bootstrap panel causality test', Journal of Happiness Studies 17(3), 1327-1336. https://doi.org/10.1007/s10902-015-9645-5

Dawkins, L., Acaster, S. \& Powell, J.H., 2007, 'The effects of smoking and abstinence on experience of happiness and sadness in response to positively valenced, negatively valenced, and neutral film clips', Addictive Behaviours 32(2), 425-431. https://doi.org/10.1016/j.addbeh.2006.05.010

Diener, E. \& Oishi, S., 2000, 'Money and happiness: Income and subjective well-being across nations', in E. Diener \& M. Eunkook (eds.), Culture and subjective wellbeing, pp. 185-218, MIT Press, Boston, MA.

Doll, R., Peto, R., Boreham, J. \& Sutherland, I., 2004, 'Mortality in relation to smoking: 50 years' observations on male British doctors', British Medical Journal 328(1) 1519-1528. https://doi.org/10.1136/bmj.38142.554479.AE

Ebrahim, A., Botha, F. \& Snowball, J., 2013, 'Determinants of life satisfaction among race groups in South Africa', Development Southern Africa 30(2), 168-185. https://doi.org/10.1080/0376835X.2013.797227

Farrelly, M.C., Nonnemaker, J.M. \& Watson, K.A., 2012, 'The consequences of high cigarette excise taxes for low-income smokers', PLOS One 7(9), e43838. https://doi.org/10.1371/journal.pone.0043838

Ferrer-i-Carbonell, A., 2005, 'Income and well-being: An empirical analysis of the comparison income effect', Journal of Public Economics 89(5-6), 997-1019. https://doi.org/10.1016/j.jpubeco.2004.06.003

Franks, P., Jerant, A.F., Leigh, J.P., Lee, D., Chiem, A., Lewis, I. et al., 2007, 'Cigarette prices, smoking, and the poor: Implications of recent trends', American Journal of prices, smoking, and the poor: Implications of recent trends/10), 1873-1877. https://doi.org/10.2105/AJP.2006.090134
Public Health 97(10)

Frey, B.S., 2008, Happiness: A revolution in economics, vol. 1, pp. 84-87, MIT Press, Cambridge, MA.

Frey, B.S., Stutzer, A., Benz, M., Meier, S., Luechinger, S. \& Benesch, C., 2010, 'Happiness: A revolution in economics', Discussed at Munich lectures in economics, MIT Press Books, Cambridge, MA
Hicks, S. 2011. The measurement of subjective wellbeing, Office for National Statistics (UK) papers, viewed 09 January 2018, from https://www.ons.gov.uk/ ons/guide-method/user-guidance/wellbeing/about-the-programme/advisoryons/guide-method/user-guidance/welloing/about-the-programme/advisory-
groups/wellbeing-technical-advisory-group/the-measurement-of-subjectivewellbeing.pdf.

Hinks, T. \& Gruen, C., 2007, 'What is the structure of South African happiness equations? Evidence from quality of life surveys', Social Indicators Research 82(2), 311-336. https://doi.org/10.1007/s11205-006-9036-8

Ho, R., 1989, 'Why do people smoke? Motives for the maintenance of smoking behaviour and its possible cessation', Australian Psychologist 24(3), 385-400. https://doi.org/10.1080/00050068908259577

Jha, P. \& Chaloupka, F.J., 2000, 'The economics of global tobacco control', British Medical Journal 321(7257), 358. https://doi.org/10.1136/bmj.321.7257.358

Koivumaa-Honkanen, H., Honkanen, R., Koskenvuo, M. \& Kaprio, J., 2003, 'Selfreported happiness in life and suicide in ensuing 20 years', Social Psychiatry and Psychiatric Epidemiology 38(1), 244-248. https://doi.org/10.1007/s00127-0030625-4

Leszczensky, L. \& Wolbring, T., 2018, How to deal with reverse causality using panel data? Recommendations for researchers based on a simulation study, viewed 20 June 2019, from https://doi.org/10.31235/osf.io/8xb4z

Mackay, J. \& Crofton, J., 1996, 'Tobacco and the developing world', British Medical Bulletin 52(1), 206-221. https://doi.org/10.1093/oxfordjournals. bmb.a011527

Murphy, S.D., 2003, 'Adoption of framework convention on tobacco control', The American Journal of International Law 97(3), 689-696. https://doi.org/ American Journal

National Treasury, 2014, Budget review 2014, p. 54, National Treasury, Pretoria.

Odermatt, R. \& Stutzer, A., 2014, 'Smoking bans, cigarette prices and life satisfaction' Presented: Beiträge zur Jahrestagung des Vereins für Socialpolitik 2014 Evidenzbasierte Wirtschaftspolitik - Session: Health III, No. C10-V3, German Economic Association, University of Munich, Munich, 20 February 2014.

Organisation for Economic Co-operation and Development (OECD), 2011, How's life? Measuring well-being, Organisation for Economic Co-operation and Development, Paris.

Oswald, A.J. \& Wu, S., 2010, 'Objective confirmation of subjective measures of human well-being: Evidence from the USA', Science 327(5965), 576-579. https://doi. org/10.1126/science.1180606

Pfeffermann, D., 1993, 'Modeling survey data', International Statistical Review 61(2), 317-337.

Pinquart, M. \& Sörensen, S., 2001, 'Gender differences in self-concept and psychological well-being in old age: A meta-analysis', The Journals of Gerontology Series B: Psychological Sciences and Social Sciences 56(4), 195-213. https://doi. Series B: Psychological Sciences
org/10.1093/geronb/56.4.P195

Remler, D.K., 2004, 'Poor smokers, poor quitters, and cigarette tax regressivity', American Journal of Public Health 94(2), 225-229. https://doi.org/10.2105/ ajph.94.2.225

Shahab, L. \& West, R., 2012, 'Differences in happiness between smokers, ex-smokers and never smokers: Cross-sectional findings from a national household survey', Drug and Alcohol Dependence 121(1), 38-44. https://doi.org/10.1016/j. drugalcdep.2011.08.011

Southern Africa Labour and Development Research Unit (SALDRU), 2016, Nationa income dynamics study 2014-2015, Wave 4 [dataset], version 1.1, SALDRU, Cape Town, DataFirst, Cape Town (distributor), Department of Planning Monitoring and Evaluation, Pretoria (commissioner).

Vaisey, S. \& Miles, A., 2017, 'What you can - And can't - Do with three-wave panel data', Sociological Methods \& Research 46(1), 44-67. https://doi.org/10.1177/ 0049124114547769

Van Walbeek, C., 2005a, 'Tobacco control in South Africa', Promotion \& Education Suppl 4, 25-28, 57-68. https://doi.org/10.1177/10253823050120040107

Van Walbeek, C., 2005b, 'The economics of tobacco control in South Africa', Doctoral dissertation, University of Cape Town, Cape Town.

Wang, M.P., Wang, X., Lam, T.H., Viswanath, K. \& Chan, S.S., 2014, 'Ex-smokers are happier than current smokers among Chinese adults in Hong Kong', Addiction 109(7), 1165-1171. https://doi.org/10.1111/add.12531

Weinhold, D. \& Chaloupka, F.J., 2016, 'Smoking status and subjective wellbeing', in Tobacco control, LSE Online Publications, London, viewed 18 January 2018, from http://eprints.Ise.ac.uk/66153/1/Weinhold_Smoking_Status.pdf.

Winship, C. \& Radbill, L., 1994, 'Sampling weights and regression analysis', Sociological Methods \& Research 23(2), 230-257.

World Health Organization (WHO), 2004, Tobacco and poverty: A vicious circle, World Health Organization, Geneva.

World Health Organization (WHO), 2015, WHO global report on trends in prevalence of tobacco smoking 2015, World Health Organization, Geneva.

Yang, Y., 2008, 'Social inequalities in happiness in the United States, 1972 to 2004: An age-period-cohort analysis', American Sociological Review 73(2), 204-226.

Yang, M. \& Zucchelli, E., 2015, The impact of public smoking bans on wellbeing externalities: Evidence from a natural experiment, Economics Working Pape Series, 2015:14, Lancaster University Management School, Lancaster.

Yawson, A.E., Baddoo, A., Hagan-Seneadza, N.A., Calys-Tagoe, B., Hewlett, S., DakoGyeke, P. et al., 2013, 'Tobacco use in older adults in Ghana: Sociodemographic characteristics, health risks and subjective wellbeing', Biomed Central Public Health 13(1), 979. 